\title{
Comparative study of vulva and abdominal skin microbiota of healthy females with high and average BMI
}

\author{
Rebecca Vongsa*, Doug Hoffman, Kristin Shepard and David Koenig
}

\begin{abstract}
Background: Obesity is known to modulate human health in a number of ways including altering the microbiome of the gut. Very few studies have examined the how obesity may affect the microbiomes of sites distant to the gut. We hypothesized that vulva and abdominal skin may be especially susceptible to body mass index (BMI)-induced alterations in biophysical properties and the microbiome due increased maceration and skin folds at those sites. The aim of this study was to determine if high BMI $(\geq 30)$ was associated with alterations in the biophysical properties and microbiomes of vulva and abdominal skin.

Results: The vulvar microbial communities of healthy reproductive-aged females were examined using 16S rRNA sequencing techniques. Our results show that vulvar pH of women with high body mass index (BMI) was statistically higher than that of women with average BMI. Phylogenetic analysis of the vulvar microbiota indicated that women with average BMI have a predominately Lactobacillus-dominated flora, whereas women with high BMI and higher pH were predominately colonized by Finegoldia and Corynebacterium. This BMl-associated shift in microbiota was not observed in samples collected from the exposed skin around the belly, indicating the effect is not global.
\end{abstract}

Conclusion: These results indicate that physiological changes associated with changes in BMl may modulate the vulva microbiome.

Keywords: Body mass index, pH, Microbiome, Microbiota, Vulva, Abdomen, And Lactobacillus

\section{Background}

The human body is inhabited by communities of microbes that have adapted to particular anatomical sites [1]. The microbial populations found in the gut and at sites outside of the gut like the skin and vagina have been linked to a variety of human health conditions including inflammatory bowel disease, ulcers, colorectal carcinoma, vaginosis, depression, psoriasis, and obesity [2-6]. With the prevalence of obesity on the rise in many countries, an increasing number of studies have been done to elucidate the mechanism and consequences of this condition. Several studies revealed a strong link between obesity and the composition of the gut microbiome [7-10] and one study demonstrated a link between obesity and the microbiome of the internal female urogenital tract [11]; however less known about

\footnotetext{
*Correspondence: rebecca.vongsa@kcc.com

Kimberly Clark Corporation, 2100 County Rd II, Neenah, WI 54956, USA
}

the effect of obesity on the microbiomes of other anatomical locations.

The skin microbiome has been well-characterized and is known to harbor distinct site-specific microbial communities that are influenced by the biophysical properties of the niche like moisture and $\mathrm{pH}$ [12-17]. The vulva is a unique region of skin that serves as a transition between the cutaneous epithelium of the skin and the mucosa of the female urogenital tract. To date, relatively few studies have been performed to characterize the microbes that colonize the vulva of healthy females. Vulvar microbial communities are thought to be of clinical importance because they regulate the proliferation of non-indigenous flora, including pathogens that can cause infection and may also affect the comfort of the urogenital area. Therefore, factors that modulate the vulvar microflora may affect comfort and health of the vulvar area.

(c) The Author(s). 2019 Open Access This article is distributed under the terms of the Creative Commons Attribution 4.0 International License (http://creativecommons.org/licenses/by/4.0/), which permits unrestricted use, distribution, and 
Obesity has been shown to affect female physiology by increasing plasma estrogen levels, elevating systemic inflammation, and reducing immune function [18-20]. We hypothesized BMI-induced physiological changes would result in altered biophysical properties of the skin which, in turn, would modulate the microbiome at those site. This study focused on abdominal and vulvar skin because it was hypothesized that these sites may be especially susceptible to BMI-induced changes in biophysical properties and microbiota structure due to increased skin folds, occlusion, and maceration. Therefore, it was the aim of this study to determine whether obesity, defined as a BMI of 30 or greater, was associated with alterations in the biophysical properties and microbiome of the vulva and abdominal skin.

\section{Results}

\section{BMI status was associated with higher $\mathrm{pH}$ in the labium}

In order to determine whether BMI altered the biophysical properties of the skin and vulvar region, the $\mathrm{pH}$ and trans-epithelial water loss (TEWL) of outer labia and exposed abdominal skin were measured. Results in Table 1 show that women in the high BMI group had a statistically higher $\mathrm{pH}$ in the vulvar region than women in the average BMI group. These results are consistent with those from a previous study that reported a positive correlation between vaginal $\mathrm{pH}$ and $\mathrm{BMI}$ [21]. The $\mathrm{pH}$ of the exposed abdominal skin was not different between the low and high BMI subjects. Table 2 shows that TEWL of exposed skin was statistically lower in the high BMI group, although still within ranges that are generally regarded as healthy $[22,23]$. These data indicate that BMI may alter specific biophysical properties of cutaneous epithelium in a site-specific manner.

\section{Bacterial community modulations in the vulva were associated with BMI}

Given that $\mathrm{pH}$ can alter the growth of a variety of microorganisms [24-26], we next hypothesized that the resident microbiota of high BMI women would be altered compared to women of low BMI in the vulvar area due to the change in $\mathrm{pH}$. This hypothesis was tested using $16 \mathrm{~S}$ rRNA sequencing analysis. Figure 1a shows the relative abundance of top bacterial genera found in the vulva

Table $1 \mathrm{pH}$ of exposed abdominal skin and outer labia in high $\mathrm{BMI}$ and normal BMI subjects

\begin{tabular}{llllc}
\hline Site & BMI status & mean & st. dev. & $p$ value \\
\hline exposed skin & average BMl & 6.069 & 1.034 & 0.080 \\
& high BMI & 6.589 & 0.965 & \\
\multirow{2}{*}{ outer labia } & average BMI & 5.925 & 0.648 & 0.035 \\
& high BMI & 6.357 & 0.582 & \\
\hline
\end{tabular}

$p$-values reported in Table 1 were calculated using a Student's t-test (95\% confidence interval)
Table 2 TEWL of exposed abdominal skin and outer labia in high $\mathrm{BMI}$ and average BMI subjects

\begin{tabular}{lllll}
\hline Site & BMl status & mean & st. dev. & $p$ value \\
\hline exposed skin & average BMl & 9.756 & 8.377 & 0.040 \\
& high BMI & 5.560 & 3.313 & \\
\multirow{2}{*}{ outer labia } & average BMl & 19.893 & 14.995 & 0.175 \\
& high BMl & 25.667 & 17.543 & \\
\hline
\end{tabular}

$p$-values reported in Table 2 were calculated using a Student's t-test (95\% confidence interval)

region (both the inner and outer labia). Lactobacillus was the most abundant genus, followed by Corynebacterium, across all vulva samples (both inner and outer labia); however, when calculated individually Corynebacterium was the most abundant species in the outer labia and Lactobacillus was the most abundant species in the inner labia. Beta diversity analysis, conducted using weighted UniFrac analysis, showed that while there was overlap, community populations of the outer labia (labia majus) clustered distinctly from the inner labia (labia minus) in agreement with previous reports [27-30] (Fig. 1b). Furthermore, Finegoldia and Lactobacillus were statistically more prevalent in the inner labia, while Corynebacterium and Staphylococcus were more prevalent in outer labia (Table 3). Beta diversity analysis using weighted UniFrac showed a distinct subpopulation of average BMI women that harbored bacterial communities that clustered separately from those of women with high BMI (Fig. 1c) while the majority average BMI women overlapped with the high BMI women. Statistical analysis of weighted UniFrac showed significant differences in vulvar bacterial communities between the inner and outer labia and average and high BMI women (Fig. 1b and c). Unweighted UniFrac analysis showed similar results (Additional file 1: Figure S1). Within the vulva (both inner and outer labia), women with average BMI had a statistically higher abundance of Lactobacillus, while Corynebacterium and Anaerococcus were more prevalent in high BMI women (Table 4). Within the inner and outer labia, women with average BMI had a statistically higher proportion of Lactobacillus (Tables 5 and 6), while Corynebacterium were more prevalent in high BMI women in the outer labia alone (Table 5). Shannon and Simpson's diversity index calculations showed differences in vulvar communities with respect to average and high BMI (Table 7). Alpha diversity analysis of inner versus outer labia showed mixed results using the two indexes (Table 8). These data indicate that changes in the vulvar microbiome may be associated with BMI status.

\section{Predicted metabolomic profiles of microbiota from high and average BMI women}

In order to examine whether high and low BMI state affected the metabolic activity of microbial communities in the vulva, we utilized the PICRUSt algorithm [31] to 


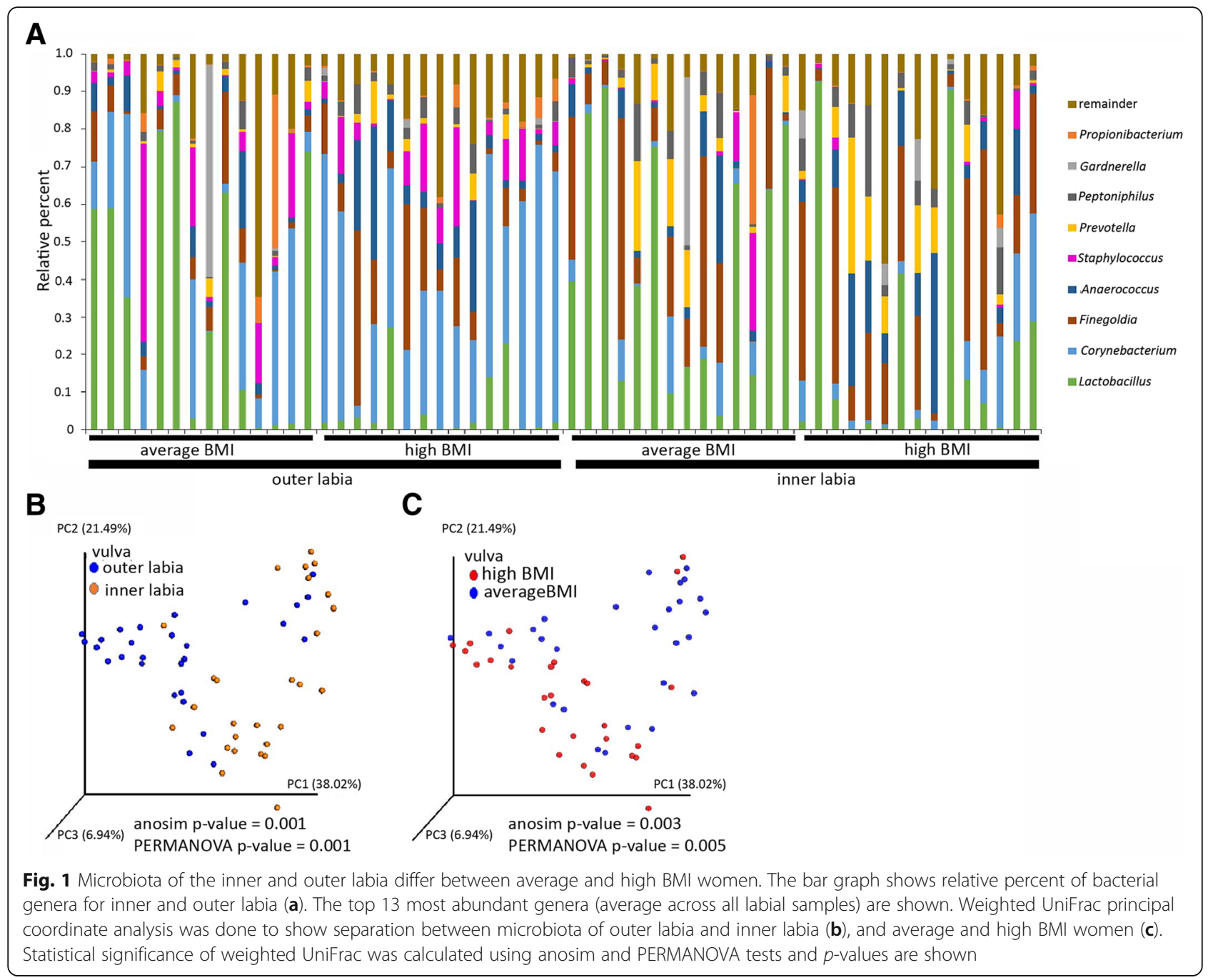

Table 3 Relative abundance of top five most abundant genera within the vulva

\begin{tabular}{lllll}
\hline Genus & Site & Mean & $\begin{array}{l}\text { Standard } \\
\text { Deviation }\end{array}$ & $p$-Value \\
\hline Corynebacterium & outer labia & 0.32 & 0.15 & 0.00 \\
& inner labia & 0.07 & 0.02 & \\
Finegoldia & outer labia & 0.10 & 0.11 & 0.02 \\
& inner labia & 0.22 & 0.19 & \\
Lactobacillus & outer labia & 0.20 & 0.28 & 0.05 \\
Staphylococcus & inner labia & 0.32 & 0.33 & \\
& outer labia & 0.09 & 0.11 & 0.00 \\
Anaerococcus & inner labia & 0.02 & 0.06 & \\
& outer labia & 0.07 & 0.09 & 0.65 \\
& inner labia & 0.09 & 0.10 & \\
\hline
\end{tabular}

$p$-values reported in Table 3 were calculated using the Kruskal-Wallis Test
Table 4 Relative abundance of top five most abundant genera within the vulva

\begin{tabular}{lllll}
\hline Genus & BMl & Mean & $\begin{array}{l}\text { Standard } \\
\text { Deviation }\end{array}$ & $p$-Value \\
\hline Corynebacterium & average & 0.13 & 0.16 & 0.04 \\
& high & 0.25 & 0.24 & \\
Finegoldia & average & 0.13 & 0.15 & 0.12 \\
& high & 0.19 & 0.17 & \\
Lactobacillus & average & 0.40 & 0.32 & 0.00 \\
Anaerococcus & high & 0.13 & 0.24 & \\
& average & 0.05 & 0.06 & 0.01 \\
Staphylococcus & high & 0.11 & 0.11 & \\
& average & 0.06 & 0.12 & 0.86 \\
& high & 0.05 & 0.07 & \\
\hline
\end{tabular}

$p$-values reported in Table 4 were calculated using the Kruskal-Wallis Test 
Table 5 Relative abundance of selected genera within the outer labia

\begin{tabular}{lllll}
\hline Genus & BMI & Mean & $\begin{array}{l}\text { Standard } \\
\text { Deviation }\end{array}$ & $p$-value \\
\hline Corynebacterium & average & 0.20 & 0.19 & 0.01 \\
& high & 0.42 & 0.21 & \\
Lactobacillus & average & 0.36 & 0.33 & 0.03 \\
& high & 0.05 & 0.09 & \\
\hline
\end{tabular}

$p$-values reported in Table 5 were calculated using the Kruskal-Wallis Test

infer their metagenomes and collapse the genes into Kyoto Encyclopedia of Genes and Genomes (KEGG) pathways at level 3 (Fig. 2). Figure 2 shows that the glycolysis/gluconeogenesis pathway was predicted to be enriched in average BMI women, while bacterial secretion systems were predicted to be enriched in high BMI women.

\section{Abdominal skin microbiota was not affected by BMI status}

In order to understand whether the BMI-associated microbiome shift was localized to the vulva or extended to an adjacent region, $16 \mathrm{~S}$ rRNA analysis was performed on microbiota samples from exposed and occluded abdominal skin. Samples from exposed skin were taken from the lower abdomens of women with average and high BMI. Occluded skin samples were taken from skin folds of women with high BMI. Figure 3a shows the percent abundance of the top nine most abundant genera for exposed and occluded skin. There was a high abundance of Staphylococcus and Corynebacterium across all samples, which is consistent with previous reports characterizing skin microflora [13-16, 32]. Despite an observed change in TEWL values (Table 2), the relative abundance of Corynebacterium, Lactobacillus, and Micrococcus in exposed skin were not statistically different between the normal and high BMI groups (Table 9). This was not surprising because TEWL values of both groups were well within the healthy range [22, 23].

In a similar study of abdominal skin microflora, Edwards et al. found a high abundance of Paenibacillus, an endospore-forming bacteria typically found in soil, on exposed and occluded abdominal skin [33] that was not observed in this study. Edwards et al. sampled only

Table 6 Relative abundance of selected genera within the inner labia

\begin{tabular}{lllll}
\hline Genus & BMI & Mean & $\begin{array}{l}\text { Standard } \\
\text { Deviation }\end{array}$ & $p$-value \\
\hline Corynebacterium & average & 0.05 & 0.06 & 0.49 \\
& high & 0.08 & 0.10 & 0.02 \\
Lactobacillus & average & 0.44 & 0.32 & \\
& high & 0.21 & 0.31 & \\
\hline
\end{tabular}

$p$-values reported in Table 6 were calculated using the Kruskal-Wallis Test
Table 7 Alpha diversity of vulvar bacterial communities by BMI

\begin{tabular}{lllll}
\hline Alpha diversity & BMl & Mean & $\begin{array}{l}\text { Standard } \\
\text { Deviation }\end{array}$ & $p$-value \\
\hline Shannon index & average & 3.57467 & 0.95033 & 0.00010 \\
& high & 4.56874 & 0.91445 & \\
Simpson's index & average & 0.78096 & 0.15236 & 0.00003 \\
& high & 0.89420 & 0.90357 & \\
\hline
\end{tabular}

p-values reported in Table 7 were calculated using the Kruskal-Wallis Test

women with a BMI $\geq 40$, while the current study sampled women with a BMI of $18-25$ or $\geq 30$. This difference in subject pool could account for the failure to detect Paenibacillus.

Principle coordinate analysis using weighted UniFrac scores showed significant overlap between exposed and occluded skin for both normal and high BMI women (Fig. 3b). These data indicate that microbiomes of non-mucosal skin, like the abdomen, may be more stable and resistant to BMI-induced physiological changes.

\section{Discussion}

Increased BMI has been associated with hypertension, coronary heart disease, type- 2 diabetes, stroke, gall bladder disease, osteoarthritis, sleep apnea, metabolic syndrome, and poor quality of life [34, 35]. Additionally, it has been shown that obesity may impact the gut microbiome causing a change in diversity and metabolic pathways [7-10]. Metabolic syndrome, which is associated with high BMI, has been shown to have a profound influence on insulin resistance and associated carbohydrate metabolism and genesis. Specifically, it has been shown that those conditions reduce glycogen levels while increasing plasma glucose levels [36, 37]. It is hypothesized that these altered conditions can have a profound effect on the structure of the vulvar microbiome.

Microbiome changes can result from both environmental and host-associated factors. With regard to environmental factors, it was observed that vulvar $\mathrm{pH}$ was different between normal and high BMI subjects. Conversely, BMI did not affect the health of the skin barrier, which would imply similar water of activity for all subjects. These data indicate that BMI alters specific biophysical properties of the labial skin like $\mathrm{pH}$; however,

Table 8 Alpha diversity of vulvar bacterial communities by site

\begin{tabular}{lllll}
\hline Alpha diversity & Site & Mean & $\begin{array}{l}\text { Standard } \\
\text { Deviation }\end{array}$ & $p$-value \\
\hline Shannon index & outer labia & 4.39629 & 0.89511 & 0.01052 \\
& inner labia & 3.78141 & 1.11852 & \\
Simpson's index & outer labia & 0.86943 & 0.10387 & 0.13750 \\
& inner labia & 0.80964 & 0.18789 & \\
\hline
\end{tabular}

$p$-values reported in Table 8 were calculated using the Kruskal-Wallis Test 

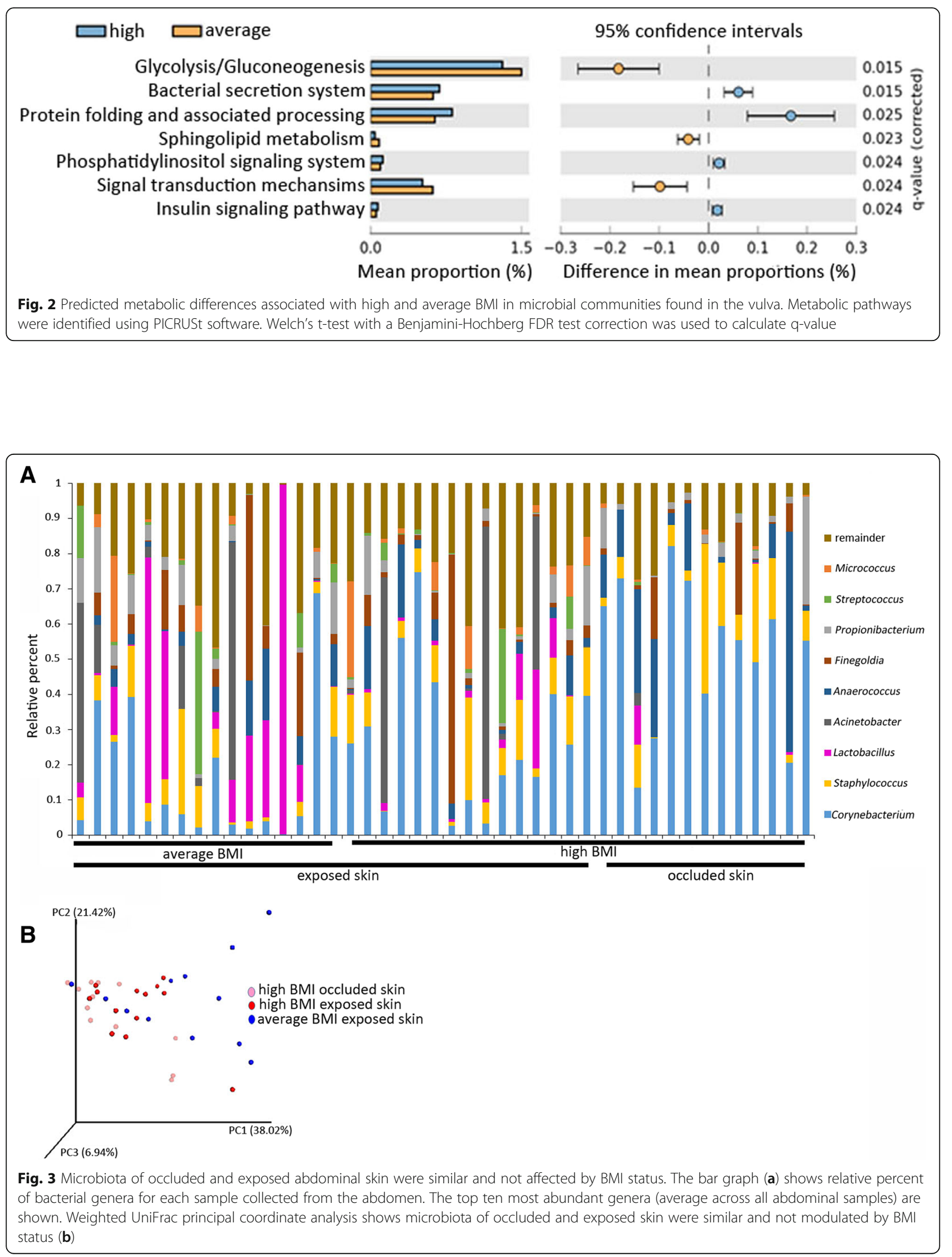
Table 9 Relative abundance of top three most abundant genera of exposed abdominal skin

\begin{tabular}{llllc}
\hline genus & BMI & Mean & $\begin{array}{l}\text { Standard } \\
\text { Deviation }\end{array}$ & -value \\
\hline Lactobacillus & average & 0.19 & 0.29 & 0.25 \\
& high & 0.04 & 0.08 & \\
Corynebacterium & average & 0.16 & 0.19 & 0.06 \\
& high & 0.28 & 0.20 & \\
Staphylococcus & average & 0.07 & 0.08 & 0.97 \\
& high & 0.10 & 0.07 & \\
\hline
\end{tabular}

$p$-values reported in Table 9 were calculated using the Kruskal-Wallis Test

BMI does not impact non-occluded skin of the abdomen, indicating that the effect is not a global phenomenon but may be specific to mucosal sites.

Within the vulva (both inner and outer labia), women with normal BMI had a statistically higher abundance of Lactobacillus, while Corynebacterium and Anaerococcus were more prevalent in high BMI women (Table 4). Women with average BMI had a statistically higher proportion of Lactobacillus in the inner and outer labia (Tables 5 and 6), while Corynebacterium were more prevalent in high BMI women in the outer labia alone (Table 5). These data indicate that changes in the vulvar microbiome may be associated with BMI status. Colonization of the vaginal tract, directly adjacent to the inner labia, is well documented and this area is known to harbor a variety of bacteria with Lactobacillus species often predominating in healthy women [38-41]. This suggests that the vulva may be a transitional zone whereby bacterial communities differ from interior to exterior, with the interior resembling vaginal microbiota and the exterior resembling skin microbiota. It is important to note that while differences in the vulvar microbiome were correlated to BMI, there are other potential factors that could influence the microbiome state that were not controlled for in this study like ethnicity and diet. More studies are needed to determine how these factors could alter the vulvar microbiome.

One explanation for the microbiome shift in high BMI subjects could be alterations of the carbon balance provided to the community by the host. Lactobacillus is well known for its ability to alter the $\mathrm{pH}$ of its environment. Provided the right conditions and appropriate carbohydrates for fermentation, Lactobacillus will produce lactic acid that will acidify the environment [42]. This process provides a competitive advantage to Lactobacillus with respect to their ability to thrive in environments where other bacteria, such as Escherichia coli, cannot [43-45]. However, these conditions appear to have changed with regard to the high BMI subjects.

The PICRUSt algorithm was employed to investigate metabolic function based on inferred metagenomes. It is important to note that while the PICRUSt algorithm is a validated method to infer metagenomes from genus level $16 \mathrm{~S}$ rRNA gene analysis it does not replace the accuracy of deep metagenomic analysis which could detect the metabolomic variation that can happen at the species and strain level. Upon analysis of the communities' metabolic patterns using PICRUSt, decreased glycolysis/ gluconeogenesis was observed among high BMI subjects (Fig. 2), which implies a change in the carbon source available to the consortia. Metabolic syndrome is known to increase serum glucose and decrease glycogen levels. A previous report demonstrated a positive correlation between Lactobacillus abundance and glycogen levels in the vagina [46]. Thus, reduced glycogen levels would put Lactobacillus at a disadvantage compared with other members of the community. Another potential factor that may have impacted Lactobacillus abundance would be the hosts' expression and activity of alpha-amylases or other enzymes required to cleave glycogen. Lactobacillus requires host enzymes to break down glycogen into subunits that it can readily utilize [47], therefore, a decrease in alpha-amylase expression or activity in high BMI women would put Lactobacillus at a disadvantage. More studies are needed to determine if amylase activity or expression is altered in high BMI women.

PICRUSt (Fig. 2) results imply that other community members are more metabolically active with respect to glucose utilization as a result of the host response to increased BMI. This study did not quantitatively measure the metabolic activities of individual members in the community so further experimentation would be needed to confirm this hypothesis. The increase in insulin signaling pathway genes (Fig. 2) in high BMI subjects further strengthens the association between an underlying metabolic syndrome in those subjects and impacts on the microbiome. Metabolic syndrome was not clinically assessed for these subjects so future studies are needed.

\section{Conclusion}

The BMI-induced changes observed in this study provide insight regarding regulation of microbiomes through host-community interactions. The loss of appropriate carbon sources appears to have limited Lactobacillus proliferation. The presumed loss of glycogen and resulting loss of pressure exerted by Lactobacillus allowed less predominant microbes to proliferate. A concomitant increase in glucose allowed dominance by other members of the community. The result was an observed increase in skin $\mathrm{pH}$ and decrease in Lactobacillus predominance associated with high BMI. Further studies are warranted, including direct measurement of glycogen/glucose levels and collection of additional subject health data to assess the presence of metabolic 
syndrome. It may also be prudent to include microbiome and associated metabolic assessments as an additional means to predict metabolic syndrome in humans. Furthermore, data suggest that adding carbon/nitrogen sources that are directly utilizable by Lactobacillus and not by other members of the community may help to sustain the vulvar microbiome in a more Lactobacillus-dominant state.

\section{Material and methods}

\section{Sample collection}

For details on how samples were collected see Additional file 2 . In short, 40 generally-healthy female subjects aged 18-35 years were enrolled, including 20 subjects (50\%) with normal BMI (18-25) and 20 subjects $(50 \%)$ high BMI $(\geq 30)$. Subjects self-reported having regular menstrual cycles for the preceding three months, had no history of skin disorders or abnormal skin conditions in the anatomical region of interest, and had no open cuts or body art in the lower torso (waist to knees). Full inclusion and exclusion criteria for this study can be found in Additional file 2. Patients volunteered to participate in the study and signed a written informed consent. Subjects were pre-screened using a script approved by the Institutional Review Board. During the first visit, subjects completed the informed consent, were screened for inclusion and exclusion criteria, and their BMI was measured. If inclusion criteria were met, the subject was asked to return between days 14 and 21 of the menstrual cycle for biophysical measurement and collection of microbiota swabs. During visit 2 , TEWL and $\mathrm{pH}$ were measured on exposed abdominal skin, inside the abdominal skin fold (high BMI women only) and the labium majus. Swabs were collected at non-overlapping sites on exposed abdominal skin, inside the abdominal skin fold (high BMI women only), and from the labium majus and labium minus. DNA was extracted and microbiota composition was determined by $16 \mathrm{~S}$ rRNA barcode modified Tag-encoded FLX amplicon pyrosequencing (bTEFAP ${ }^{\mathrm{rm}}$ ) using a previously described protocol [48]. Sequences were submitted to the Sequence Read Archive (SRA) under accession number SRP116641.

\section{Data analysis}

The Quantitative Insights into Microbial Ecology (QIIME) 1.9.0 data analysis tool was used for used for subsequent $16 \mathrm{~S}$ rRNA data analysis. Sequences were de-mutiplexed and operational taxonomic unit (out) tables constructed using closed reference OTU picking against the Greengenes reference database (version 13_8) at $97 \%$ identity, and the remaining OTUs were discarded [49]. After quality filters there were a total of 865,634 reads. An average of 7154 counts per sample. Samples with less than 1020 counts were excluded from the analysis. Rarefaction curves showed that very few additional OTUs were observed after 1020 reads. Taxonomy was assigned based on the Greengenes reference database. Alpha diversity metrics were calculated in QIIME 1.9.0. Beta diversity evaluations were done in QIIME 1.9.0 using weighted and unweighted UniFrac metrics and visualized using principle coordinates analysis (PCoA) [50, 51]. PICRUSt was used to predict metagenomes and collapse the genes into KEGG pathways (level 3).

\section{Statistical analysis}

Linear regression and t-tests were used to determine whether $\mathrm{pH}$ and TEWL were related to BMI status. Significance was defined at $p \leq 0.0500$. Statistical Analysis of Metagenomic Profiles (STAMP) was used to determine differences in the KEGG functions between the high and average BMI groups. Welch's t-test with a Benjamini-Hochberg FDR test correction was used to calculate q-value. Differences in alpha diversity metrics and relative abundance of bacterial genera were calculated using Kruskal-Wallis tests. Differences in beta diversity metrics were calculated using anosim and PERMANOVA tests. $P$ values less than or equal to 0.05 were considered significant and values were reported.

\section{Additional files}

Additional file 1: Figure S1. Unweighted UniFrac principal coordinate analysis was done to show separation between microbiota of outer labia and inner labia (a), average and high BMI of the outer labia (B) and inner labia (C). (JPG 97 kb)

Additional file 2: Study Protocol. (PDF $337 \mathrm{~kb}$ )

\section{Abbreviations}

BMI: Body mass index; IRB: Institutional review board; KEGG: Kyoto encyclopedia of genes and genomes; OTU: Operational taxonomic units; PCOA: Principal coordinates analysis; PCR: Polymerase chain reaction; PICRUSt: Phylogenetic investigation of communities by reconstruction of unobserved states; QIIME: Quantitative Insights into microbial ecology; rRNA: Ribosomal ribonucleic acid; SRA: Sequence read archive; TEWL: Transepithelial water loss

Acknowledgements

The authors would like to acknowledge Cindy Gould for coordinating the study and managing study documents, and the staff at Kimberly Clark's

Clinical Research Services for their diligent work in collecting the samples.

\section{Funding}

Research was funded by the Kimberly Clark Corporation. Employees of Kimberly Clark were responsible for the design of the study, collection, analysis, interpretation of the data, and writing of the manuscript.

\section{Availability of data and materials}

All data generated or analyzed during this study are included in this published article and its supplementary information files. Sequences were submitted to SRA (www.ncbi.nlm.nih.gov/sra) under accession number SRP116641. 


\section{Authors' contributions}

RV and DK designed the study, performed data analysis, and wrote the manuscript. DH contributed to data analysis and drafting of the manuscript. KS designed the study, led collection of clinical samples, and contributed toward drafting the manuscript. All authors approved the final manuscript.

\section{Ethics approval and consent to participate}

The study was approved by New England Institutional Review Board (IRB\#12-160). Each subject gave written consent after the nature of the study has been fully explained by the Investigator or designee. Ample time for questions and answers was provided during the consenting process.

\section{Consent for publication}

Not applicable.

\section{Competing interests}

All authors are employed by the Kimberly Clark Corporation.

\section{Publisher's Note}

Springer Nature remains neutral with regard to jurisdictional claims in published maps and institutional affiliations.

\section{Received: 23 March 2018 Accepted: 9 January 2019}

\section{Published online: 17 January 2019}

\section{References}

1. Costello EEK, Lauber CCL, Hamady M, Fierer N, Gordon Jl, Knight R. Bacterial community variation in human body habitats across space and time. Science (80- ). 2009;326(5960):1694-7.

2. Wikoff WR, Anfora AT, Liu J, Schultz PG, Lesley SA, Peters EC, Siuzdak G. Metabolomics analysis reveals large effects of gut microflora on mammalian blood metabolites. Proc Natl Acad Sci. 2009;106(10):3698-703.

3. Gacias M, Gaspari S, Santos P-MG, Tamburini S, Andrade M, Zhang F, Shen N, Tolstikov V, Kiebish MA, Dupree JL, Zachariou V, Clemente JC, Casaccia P. Microbiota-driven transcriptional changes in prefrontal cortex override genetic differences in social behavior. Elife. 2016;5

4. Clemente JC, Pehrsson EC, Blaser MJ, Sandhu K, Gao Z, Wang B, Magris M, Hidalgo G, Contreras M, Noya-Alarcon O, Lander O, McDonald J, Cox M, Walter J, Oh PL, Ruiz JF, Rodriguez S, Shen N, Song SJ, Metcalf J, Knight R, Dantas G, Dominguez-Bello MG. The microbiome of uncontacted Amerindians. Sci Adv. 2015;1(3):e1500183-3.

5. Cho I, Blaser MJ. The human microbiome: at the interface of health and disease. Nat Rev Genet. 2012;13(4):260-70.

6. S. Shivaji, "We are not alone: a case for the human microbiome in extra intestinal diseases.", Gut Pathog, vol. 9, no. 1, p. 13, Dec. 2017.

7. Turnbaugh PJ, Hamady M, Yatsunenko T, Cantarel BL, Duncan A, Ley RE, Sogin ML, Jones WJ, Roe BA, Affourtit JP, Egholm M, Henrissat B, Heath AC, Knight $\mathrm{R}$, Gordon Jl. A core gut microbiome in obese and lean twins. Nature. 2009:457(7228):480-4.

8. Turnbaugh PJ, Gordon Jl. The core gut microbiome, energy balance and obesity. J Physiol. 2009;587(Pt 17):4153-8.

9. P. J. Turnbaugh, R. E. Ley, M. a Mahowald, V. Magrini, E. R. Mardis, and J. I. Gordon, "An obesity-associated gut microbiome with increased capacity for energy harvest.", Nature, vol. 444, no. 7122, pp. 1027-1031, 2006.

10. Ley RE, Backhed F, Turnbaugh P, Lozupone CA, Knight RD, Gordon Jl. Obesity alters gut microbial ecology. Proc Natl Acad Sci. 2005;102(31):11070-5.

11. Oh HY, Seo S-S, Kong J-S, Lee J-K, Kim MK. Association between obesity and cervical microflora dominated by lactobacillus iners in Korean women. J Clin Microbiol. 2015;53(10):3304-9.

12. Capone KA, Dowd SE, Stamatas GN, Nikolovski J. Diversity of the human skin microbiome early in life. J. Invest. Dermatol. 2011;131(10):2026-32.

13. Grice EA, Segre JA. The skin microbiome. Nat Rev Microbiol. 2011:9(4):244-53.

14. Grice EA, Kong HH, Conlan S, Deming CB, Davis J, Young AC, Comparative Sequencing Program NISC, Bouffard GG, Blakesley RW, Murray PR, Green ED, Turner ML, Segre JA. Topographical and temporal diversity of the human skin microbiome. Science. 2009;324(5931):1190-2.

15. Schommer NN, Gallo RL. Structure and function of the human skin microbiome. Trends Microbiol. 2013;21(12):660-8.

16. Oh J, Byrd AL, Park $M$, Kong HH, Segre JA. Temporal stability of the human skin microbiome. Cell. 2016;165(4):854-66.
17. Sanford JA, Gallo RL. Functions of the skin microbiota in health and disease. Semin Immunol. 2013;25(5):370-7.

18. Lunenfeld B, Arulkumaran S, Calleja-Agius J, Brincat M, Borg M. Skin connective tissue and ageing. Best Pract Res Clin Obstet Gynaecol. 2013; 27(5):727-40.

19. Calle EE, Kaaks R. Overweight, obesity and cancer: epidemiological evidence and proposed mechanisms. Nat Rev Cancer. 2004;4(8):579-91.

20. Choi J, Joseph L, Pilote L. Obesity and C-reactive protein in various populations: a systematic review and meta-analysis. Obes Rev. 2013;14(3):232-44.

21. Pereira Da Silva D, Martinez De Oliveira J, Negreiro F. Observational study of vaginal pH in healthy Portuguese women. Minerva Ginecol. 2011;63(2):203-12.

22. Nikolovski J, Stamatas GN, Kollias N, Wiegand BC. Barrier function and waterholding and transport properties of infant stratum Corneum are different from adult and continue to develop through the first year of life. J Invest Dermatol. 2008:128(7):1728-36.

23. Mack MC, Chu MR, Tierney NK, Ruvolo E, Stamatas GN, Kollias N, Bhagat K, Ma L, Martin KM. Water-holding and transport properties of skin stratum Corneum of infants and toddlers are different from those of adults: studies in three geographical regions and four ethnic groups. Pediatr Dermatol. 2016;33(3):275-82

24. LeBlanc JG, Garro MS, Savoy de Giori G. Effect of pH on lactobacillus fermentum growth, raffinose removal, alpha-galactosidase activity and fermentation products. Appl Microbiol Biotechnol. 2004;65:119-23.

25. Duncan SH, Louis $\mathrm{P}$, Thomson JM, Flint HJ. The role of $\mathrm{pH}$ in determining the species composition of the human colonic microbiota. Environ Microbiol. 2009:11(8):2112-22.

26. Fernández-Calviño D, Rousk J, Brookes PC, Bååth E. Bacterial pH-optima for growth track soil $\mathrm{pH}$, but are higher than expected at low pH. Soil Biol Biochem. 2011;43(7):1569-75.

27. Brown CJ, Wong M, Davis CC, Kanti A, Zhou X, Forney LJ. Preliminary characterization of the normal microbiota of the human vulva using cultivation- independent methods. Printed in Great Britain. 2007:271-6.

28. Shiraishi T, Fukuda K, Morotomi N, Imamura Y, Mishima J, Imai S, Miyazawa $\mathrm{K}$, Taniguchi $\mathrm{H}$. Influence of menstruation on the microbiota of healthy women's labia minora as analyzed using a 16s rRNA gene-based clone library method. Jpn J Infect Dis. 2011:64(1):76-80.

29. Jayaram A, Witkin SS, Zhou X, Brown CJ, Rey GE, Linhares IM, Ledger WJ, Forney $\sqcup$. The bacterial microbiome in paired vaginal and vestibular samples from women with vulvar vestibulitis syndrome. Pathog Dis. 2014.

30. Gajer P, Brotman RM, Bai G, Sakamoto J, Schutte UME, Zhong X, Koenig SSK, Fu L, Ma Z, Zhou X, Abdo Z, Forney LJ, Ravel J. Temporal dynamics of the human vaginal microbiota. Sci Transl Med. 2012;4(132):132ra52-2.

31. Langille MMGI, Zaneveld J, Caporaso JG, McDonald D, Knights D, Reyes JAJ, Clemente JJC, Burkepile DE, Vega Thurber RRL, Knight R, Beiko RGR, Huttenhower C. Predictive functional profiling of microbial communities using 16 S rRNA marker gene sequences. Nat Biotechnol. 2013;31(9):814-21.

32. Kong HH, Segre JA. Skin microbiome: looking back to move forward. J. Invest. Dermatol. 2012;132(3 Pt 2):933-9.

33. Edwards RK, Kumar R, Zhi D, Szychowski J, Subramaniam A, Lefkowitz EJ, Morrow C. Gravidas with class III obesity: evealuating the abdominal skin microbiota above and below the panniculus. J Matern Fetal Neonatal Med. 2016;29(20):3312-6.

34. Tukker A, Visscher T, Picavet H. Overweight and health problems of the lower extremities: osteoarthritis, pain and disability. Public Health Nutr. 2008; 12(3):1

35. Hubbard VS. Defining overweight and obesity: what are the issues? Am J Clin Nutr. 2000;72(5):1067-8.

36. Kaur J. A comprehensive review on metabolic syndrome. Cardiol Res Pract. 2014:2014:1-21.

37. Petersen KF, Dufour S, Savage DB, Bilz S, Solomon G, Yonemitsu S, Cline GW, Befroy D, Zemany L, Kahn BB, Papademetris X, Rothman DL, Shulman $\mathrm{Gl}$. The role of skeletal muscle insulin resistance in the pathogenesis of the metabolic syndrome. Proc Natl Acad Sci. 2007;104(31):12587-94.

38. Ravel J, Gajer P, Abdo Z, Schneider GM, Koenig SSK, McCulle SL, Karlebach S, Gorle R, Russell J, Tacket CO, Brotman RM, Davis CC, Ault K, Peralta L, Forney LJ. Vaginal microbiome of reproductive-age women. Proc Natl Acad Sci U S A. 2011;108(Supplement_1):4680-7.

39. Ma B, Forney LJ, Ravel J. Vaginal microbiome: rethinking health and disease. Annu Rev Microbiol. 2012;66:371-89.

40. Bisanz JE, Seney S, McMillan A, Vongsa R, Koenig D, Wong L, Dvoracek B, Gloor GB, Sumarah M, Ford B, Herman D, Burton JP, Reid G. A systems 
biology approach investigating the effect of probiotics on the vaginal microbiome and host responses in a double blind, placebo-controlled clinical trial of post-menopausal women. PLoS One. 2014;9(8):e104511.

41. Hummelen R, Macklaim JM, Bisanz JE, Hammond J-AA, McMillan A, Vongsa R, Koenig D, Gloor GB, Reid G. Vaginal microbiome and epithelial gene array in post-menopausal women with moderate to severe dryness. PLoS One. 2011;6(11):e26602.

42. Boskey ER, Telsch KM, Whaley K, Moench TR, Cone RA. Acid production by vaginal flora in vitro is consistent with the rate and extent of vaginal acidification. Infect Immun. 1999;67(10):5170-5.

43. Vongsa RA, Minerath RA, Busch MA, Tan J, Koenig DW. In vitro evaluation of nutrients that selectively confer a competitive advantage to lactobacilli. Benef Microbes. 2016;7(2):299-304.

44. Juárez Tomás MS, Ocaña VS, Wiese B, Nader-Macías ME. Growth and lactic acid production by vaginal lactobacillus acidophilus CRL 1259, and inhibition of uropathogenic Escherichia coli. J Med Microbiol. 2003;52(Pt 12):1117-24.

45. Rousseau V, Lepargneur JP, Roques C, Remaud-Simeon M, Paul F. Prebiotic effects of oligosaccharides on selected vaginal lactobacilli and pathogenic microorganisms. Anaerobe. 2005;11(3):145-53.

46. Mirmonsef P, Hotton AL, Gilbert D, Burgad D, Landay A, Weber KM, Cohen M, Ravel J, Spear GT. Free glycogen in vaginal fluids is associated with lactobacillus colonization and low vaginal pH. PLoS One. 2014;9(7):e102467.

47. Spear GT, McKenna M, Landay AL, Makinde H, Hamaker B, French AL, Lee B$\mathrm{H}$. Effect of pH on cleavage of glycogen by vaginal enzymes. PLoS One. 2015;10(7):e0132646.

48. Dowd SE, Callaway TR, Wolcott RD, Sun Y, McKeehan T, Hagevoort RG Edrington TS. Evaluation of the bacterial diversity in the feces of cattle using 16S rDNA bacterial tag-encoded FLX amplicon pyrosequencing (bTEFAP). BMC Microbiol. 2008;8(1):125.

49. DeSantis TZ, Hugenholtz P, Larsen N, Rojas M, Brodie EL, Keller K, Huber T, Dalevi D, Hu P, Andersen GL. Greengenes, a chimera-checked 165 rRNA gene database and workbench compatible with ARB. Appl Environ Microbiol. 2006;72(7):5069-72.

50. Lozupone C, Knight R. UniFrac: a new phylogenetic method for comparing microbial communities. Appl Environ Microbiol. 2005;71(12):8228-35.

51. Vázquez-Baeza Y, Pirrung M, Gonzalez A, Knight R. EMPeror: a tool for visualizing high-throughput microbial community data. Gigascience. 2013;2(1):16.

Ready to submit your research? Choose BMC and benefit from:

- fast, convenient online submission

- thorough peer review by experienced researchers in your field

- rapid publication on acceptance

- support for research data, including large and complex data types

- gold Open Access which fosters wider collaboration and increased citations

- maximum visibility for your research: over $100 \mathrm{M}$ website views per year

At BMC, research is always in progress.

Learn more biomedcentral.com/submissions 